\title{
The Relation Between Economical And Environmental Factors And Malaria Incidence In Khartoum State-Sudan
}

\author{
Afaf T. Mahgoub \\ Traditional Medicine Department, Medicinal and Aromatic and Traditional Medicine Research \\ Institute, National Center for Research, Sudan.
}

\begin{abstract}
Malaria incidence is intimately linked to environmental quality and economic status of the family. However, few studies have evaluated the associations between environmental factors and economic status of families and prevalence of malaria among their children. Prospective population-based study on malaria was carried in Khartoum State. Sample size was $\mathbf{4 0 0}$ families, distributed between three different socioeconomic strata. Different quantitative and qualitative methods of data collection were used (questionnaires, interviews and observations). The prevalence of malaria was performed for children under five years old. The study found that income was the strongest influencing factor $(P=0.000)$ affecting negatively the prevalence of Malaria among children through affecting standard of living. Also there is strong relation between environmental factors (such as pit latrine and home size) and prevalence of malaria Poverty and poor environment in home and around lead to increase malaria incidence.
\end{abstract}

Keywords: Malaria, environment factors, socioeconomic status, traditional prevention, children diseases.

\section{INTRODUCTION}

Human health and well-being are intimately linked to environmental quality. A clean environment is essential for human health and well-being. However, the interactions between the environment and human health are highly complex and difficult to assess. An estimated $24 \%$ of the global disease burden and $23 \%$ of all deaths can be attributed to environmental factors (WHO, 2006). This makes the use of the precautionary principle particularly useful. The best-known health impacts are related to ambient air pollution, poor water quality and insufficient sanitation. Malaria is an important health problem of developing countries. Malaria incidence in Sudan was estimated to be about 9 million episodes in 2002 and the number of deaths due to malaria was about 44,000. Children under five years of age had the highest burden and males had the highest incidence and mortality (Abdalla, 2007). 


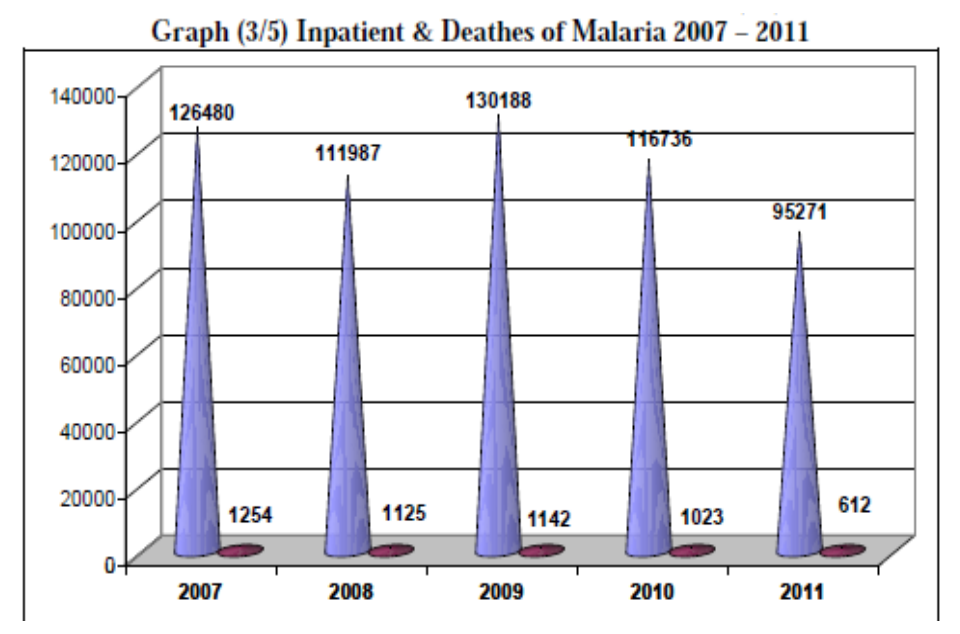

From graph the inpatient and death by malaria increase in 2007 and 2009 and relatively decease in 2011.

In Sudan, prevention relied heavily on vector control through insecticide spray, with minimum efforts toward early diagnosis and treatment. Bed nets have been in use for a long time.

This disease to a great extend was known to be related to sanitation of the house and the environment of the area surround it (Abd/ El-Gayoum et al (2009), Abbas (1994), Prathiba et al (2012). Households which have toilet facilities clean drinking water, and a greater number of rooms and mosquito nets in the rooms, have less chance to infect by malaria (Ayele et al, 2013). Therefore, this disease is prevalence in low socioeconomic areas (Tusting et al, 2013).

Poor families live in dwellings that offer little protection against mosquitoes. Improper excreta disposable will lead to soil and water pollution and food contamination and propagation of flies and other insects. This pollution and insects will affect home environment and family health. Annual health statistical report 2011 shows that malaria represents the second place (11.4\%) among diseases leading to health units (children less than five years). But fortunately, Malaria recently is being out of ten diseases leading to death in hospitals for children less than five years (AHSR, 2011).

There are many factors contributed to the spread of malaria in Khartoum State, such as climate variables (rainfall, Temperature..etc)( Rasha etal, 2011). Also, large expansion of agricultural schemes particularly around residential areas, bad drainage system, the presence of an old decayed water piped net work, which is subject to continue breaks. All these factors provide suitable breeding grounds for vectors carrying diseases.

Traditional medicine is embedded in the Sudanese culture. Many authors talked about its old roots in Sudanese societies (Ibn def alla, 1974), (Alsafi, 1970)...etc. In Sudan popular health system play a major role in the health of people. The mother usually treats and prevents physical and spiritual diseases in home. Many mothers use some medicinal plants to treat or prevent from malaria. Some of them used the bark of Cinchona succiruba and fruits of Tamarindus indica used as drink, and other eat seven seeds from Corton zambesicus in the morning. Home remedies to malaria complication used also by mothers in Tanzania (Tarimo, 2000). 
The study aims to determining the prevalence of malaria in Khartoum State, and investigate the relationship between economic and environmental factors with malaria incidence.

\section{Study setting and participants}

\section{MATERIAL AND METHODS}

This study was carried in Khartoum State, which is located between latitudes 15026' and $15^{\circ} 45^{\prime} \mathrm{N}$ and longitudes $32^{\circ} 25^{\prime}$ and $32^{\circ} 40^{\prime} \mathrm{E}$, at an altitude of $405.6 \mathrm{~m}$ above sea level. In the last census 2008 Khartoum total population was (5.7) million.

\section{Sample size}

The sampling unit used in the study was the family, which was defined as a group of individuals living together in a household. The family usually included the father, mother, offspring, and sometimes grandparents, aunts, and uncles. Research sample was 400 families.

\section{Sample selection}

A multistage random stratified sampling technique was employed for the selection of the study population in this comparative study. The sample size (400 families) was divided into three strata: 120 families from Alriyad to represent the high socio-economical status (HSS), 180 families from Gebra representing the middle socio-economical status (MSS), and 100 families from Alremala representing the lower socio-economical status (LSS). The strata were distributed proportionally according to the size of the population in the catchment area for each center.

\section{QUESTIONNAIRE}

A structured questionnaire was designed to fulfill the study objectives. It consisted of four sections: The first section was concerned with the personal and socio demographic characteristics of the participants (e.g., age, sex, and education). The second section of questionnaire is about economic status of the family (different sources of income). The third section is about environmental elements in home and surrounded areas. The fourth section is about malaria prevalence among children, and treatment type used for it (traditional or modern medicine).

The questionnaire design was the outcome of many steps including comprehensive literature review, and three referees reviewed it. To refine the questionnaire, a pilot study was undertaken to test the reliability of the questionnaire, and was completed by 21 volunteers in the three areas.

Data were collected during 2012.

\section{DATA COLLECTION}

\section{STATISTICAL ANALYSIS}

For the comparisons, the $\chi^{2}$ test at $99 \%$ level of significance $(p=0.01)$ was used. Data were analyzed by the SPSS program (statistical package for social sciences), the results presented by percentage and chi square test. 


Table (1) Demographic characteristics of families
\begin{tabular}{|l|l|l|}
\hline $\begin{array}{l}\text { Family size } \\
\leq 5\end{array}$ & 290 & $72.5 \%$ \\
\hline$>5$ & 110 & $27.5 \%$ \\
\hline $\begin{array}{l}\text { Children Age } \backslash \text { sex } \\
\text { Male } \leq 5\end{array}$ & 136 & $52.3 \%$ \\
\hline Female $\leq 5$ & 124 & $47.7 \%$ \\
\hline $\begin{array}{l}\text { Family income } \\
<301 \$\end{array}$ & 268 & $67 \%$ \\
\hline$>300 \$$ & 132 & $33 \%$ \\
\hline
\end{tabular}

Source: fieldwork 2012

The table above showed that a high percentage (72.5\%) of families' members less or equal to five, which reflects that family's size is relatively small. Considering sex distribution among children; the percentage of male $(52.3 \%)$ relatively higher than female $(47.7 \%)$.

Significantly, higher percentage (67\%) of families earn less than $301 \$$, this definitely Reflects the poverty among this population.

Table (2) Malaria spread among children

\begin{tabular}{|c|l|l|l|}
\hline \multirow{2}{*}{ Areas } & \multicolumn{3}{|l|}{ Total } \\
\multicolumn{2}{|l|}{ Malaria } & \\
\hline & Yes & No & \\
\hline Alriyad(HSS) & 0 & 80 & 80 \\
& $.0 \%$ & $100.0 \%$ & $100.0 \%$ \\
\hline Gebra(MSS) & 13 & 101 & 114 \\
& $11.4 \%$ & $88.6 \%$ & $100.0 \%$ \\
\hline Alremela(LSS) & 7 & 59 & 66 \\
& $10.6 \%$ & $89.4 \%$ & $100.0 \%$ \\
\hline Total & 20 & 240 & 260 \\
& $7.7 \%$ & $92.3 \%$ & $100.0 \%$ \\
\hline
\end{tabular}

Source: fieldwork 2012

The table above showed that there is a strong relation between residential areas with malaria. Malaria prevalence in Gebra (MSS) was higher probably because of the unhealthy environment of the area, a lot of mosquitoes during most of the seasons. This was detected by chi square test $(\mathrm{P}=0.008)$. The surrounded area usually affected the spread of malaria more than home environment, this was clear from the results of the spread of insects, and these results agree with Abbas (1994) study. However, it was found that $85 \%$ from children infected by malaria their mothers complaining from mosquitoes all seasons. 


\section{Table (3) the relation between families incomes and infected by malaria}

\begin{tabular}{|c|c|c|c|c|}
\hline & & Mala & & \\
\hline & Income & Yes & No & Total \\
\hline & $<301 \$$ & 20 & 148 & 168 \\
\hline & & $11.9 \%$ & $88.1 \%$ & $100.0 \%$ \\
\hline & $>300 \$$ & 0 & 92 & 92 \\
\hline & & $.0 \%$ & $100.0 \%$ & $100.0 \%$ \\
\hline Total & & 20 & 240 & 260 \\
\hline & & $7.7 \%$ & $92.3 \%$ & $100.0 \%$ \\
\hline
\end{tabular}

$\mathrm{Chi}^{2}-\mathrm{P}=\mathbf{0 . 0 0 0}$

Source: fieldwork 2012

The relation between family income and incidence of malaria was clear in table above all cases of malaria exist among family earns less than $301 \$$. Family income has a great influence in taking nutritional foods, house standard of living and availability of medical care. Moreover, income determines the availability of measurement using to fight mosquitoes, this agrees with Tusting et al (2013) study.

Table (4) mosquitoes in the three areas

\begin{tabular}{|c|c|c|c|c|c|}
\hline & \multirow[t]{2}{*}{$\begin{array}{l}\text { Spread of } \\
\text { mosquitoes }\end{array}$} & \multicolumn{3}{|l|}{ Area } & \multirow[b]{2}{*}{ Total } \\
\hline & & Alriyad & Gebra & Alremela & \\
\hline & \multirow[t]{2}{*}{ Yes } & 39 & 145 & 70 & 254 \\
\hline & & $32.5 \%$ & $80.6 \%$ & $70.0 \%$ & $63.5 \%$ \\
\hline & \multirow[t]{2}{*}{ No } & 57 & 20 & 10 & 87 \\
\hline & & $47.5 \%$ & $11.1 \%$ & $10.0 \%$ & $21.8 \%$ \\
\hline & \multirow[t]{2}{*}{ in some seasons } & 24 & 15 & 20 & 59 \\
\hline & & $20.0 \%$ & $8.3 \%$ & $20.0 \%$ & $14.7 \%$ \\
\hline \multirow{2}{*}{\multicolumn{2}{|c|}{ Total }} & 120 & 180 & 100 & 400 \\
\hline & & $100.0 \%$ & $100.0 \%$ & $100.0 \%$ & $100.0 \%$ \\
\hline
\end{tabular}

From the table above (32.5\%) of Alriyad's residents were complaining from mosquitoes all seasons. Whereas, a high percentage (80.6\%) of Gebra's residents complaining from mosquitoes all seasons, which represent the worst area according to spread of mosquitoes. Alremela also have a bad environment (70\%) from its resident complaining from mosquitoes.

The environment around the house may be provides a suitable breeding ground for a wide range of vectors carrying diseases. Flies breeding and feeding in the scattered garbage around the houses or streets transmit diarrheal diseases, and where mosquitoes breeding in stagnant water cause malaria. All these reasons and others help in made bad and unhealthy environment. Even the family care about home environment and aware about preventive methods, the insects come from surrounded areas. This leads to increase malaria in this period. 
It is noticed that Alriyad's streets are wide and clean, and garbage was collected by a proper way. Moreover most families care about cleaning near their houses, which is taken by their servants. From interviews with Gebra's mothers, they mentioned that the problem of unhealthy environment is due to many reasons; firstly the empty places, hence some poor families live as squatter settlement. Where they lack, the basic infrastructures essential for life and good health e.g. water supply, garbage collection and latrine. Second reason is the rare of channels and stagnate water after rain fall. These reasons lead to unhealthy environment with spread of flies, insects and mosquitoes carrying diseases like malaria and diarrhea.

In Alremela the problem of bad environment concentrated in narrow streets and spread of pit latrine, which lead to increase flies. Moreover, people live near river (western area of Alremela) believing that agriculture projects have contributed enough to increase of mosquitoes. The spread of insects and mosquitoes affected the distribution of diseases in these areas.

\section{Table (5) The relation between bath types and mosquitoes spread}

\begin{tabular}{|c|c|c|c|c|}
\hline & & Bath type & & \\
\hline & $\begin{array}{l}\text { Exist } \\
\text { mosquitoes }\end{array}$ & $\begin{array}{l}\text { Tradition } \\
\text { (pit } \\
\text { latrine) }\end{array}$ & Siphon & Total \\
\hline & Yes & 42 & 212 & 254 \\
\hline & & $75.0 \%$ & $61.6 \%$ & $63.5 \%$ \\
\hline & No & 7 & 80 & 87 \\
\hline & & $12.5 \%$ & $23.3 \%$ & $21.8 \%$ \\
\hline & In some seasons & 7 & 52 & 59 \\
\hline & & $12.5 \%$ & $15.1 \%$ & $14.8 \%$ \\
\hline Total & & 56 & 344 & 400 \\
\hline & & $100.0 \%$ & $100.0 \%$ & $100.0 \%$ \\
\hline
\end{tabular}

Source: fieldwork 2012

The table above showed that majority (75\%) from families who have pit latrine suffering from mosquitoes all seasons. Families which have toilet facilities have less chance of having mosquitoes, which agree with Ayele et al (2013) study. 


\section{Table (5) The relation between malaria incidence and home size}

\begin{tabular}{|c|c|c|c|c|}
\hline & $\begin{array}{l}\text { Number of } \\
\text { rooms }\end{array}$ & $\mathrm{Ma}$ & & \\
\hline & & Yes & No & Total \\
\hline & $\leq 3$ & 12 & 97 & 108 \\
\hline & & $11.1 \%$ & $89.9 \%$ & $100 \%$ \\
\hline & $>3$ & 8 & 144 & 152 \\
\hline & & $5.3 \%$ & $94.7 \%$ & $100 \%$ \\
\hline Total & & 20 & 240 & 260 \\
\hline & & $7.7 \%$ & $92.3 \%$ & $100.0 \%$ \\
\hline
\end{tabular}

Source: fieldwork 2012

Home size has influencing factor affecting spread of mosquitoes in home. This clear from table above the percentage of children (11.1\%) infected by malaria live in home with $\leq 3$ rooms compared with $5.3 \%$ children live in home with $>3$ rooms. The negative relation between home size and malaria incidence is confirmed by Ayele et al (2013) study.

Table (6) The relation between income and measures to fight mosquitoes

\begin{tabular}{|l|r|r|r|}
\hline \multirow{2}{*}{ Measures } & \multicolumn{2}{|c|}{ Income } & \\
\cline { 2 - 4 } & $\begin{array}{c}\text { less than } \\
301 \$\end{array}$ & $\begin{array}{c}\text { more than } \\
300 \$\end{array}$ & Total \\
\hline Smoking & 106 & 9 & 115 \\
& $46.9 \%$ & $13 \%$ & $39 \%$ \\
\hline Spray & 95 & 58 & 153 \\
& $42.0 \%$ & $84.1 \%$ & $51.9 \%$ \\
\hline bed nets with others & 18 & 0 & 18 \\
measures & $8 \%$ & $.0 \%$ & $6.1 \%$ \\
\cline { 2 - 4 } & 7 & 2 & 9 \\
regular cleaning & $3.1 \%$ & $2.9 \%$ & $3 \%$ \\
\hline & 226 & 69 & 295 \\
& $100.0 \%$ & $100.0 \%$ & $100.0 \%$ \\
\hline
\end{tabular}

Source: fieldwork 2012

It is well known that mosquitoes transmitted parasite of Malaria. Therefore it is important to fight it by effective measures in addition to regular home cleaning. The table above shows that $51.9 \%$ of all sample using spray to fight mosquitoes. The majority (84.1\%) of families who earns more than $300 \$$ using it. Spray is effective measure to fight mosquitoes, but it's expensive and not available to most common people. Whereas the percentage of families used smoking (traditional methods) 64.7\% earn less than 301\$ compared with $13 \%$ families earn more than $300 \$$, and it is clear that the percentage increase with income. The common smoking used to fight mosquitoes in Sudan is Acacia seyal Del. Minority percentage (6.1\%) and (3\%) used bed nets with other measurement and depend on regular cleaning to decreased mosquitoes respectively. 
It is observed that the common type of families in Sudan is the extended families. Hence, the grandmother still plays a major role in providing health care for all members of the families. The study found that there is a negative relation between family income and using home remedies, a high percentage $(37.3 \%)$ of mothers who selected home remedies as the first choice in the case of illness, their families' earned less than $301 \$$ monthly, because economic status affecting directly the selection of treatment types by the determination of facilities and access to medical treatment, and that agreed with Abdalla study (2003).

Famous prevention mixture used by some families constituted from six plants mixed with bee honey: Solenostemma argel. Acacia nilotica, Tamarindus indica, Cymbopogon schoenanthus, Hibiscus sabdriffa and Phoenix dactylifera. From interviews, some families used in the treatment the bark of Cinchona succiruba and Khaya senegalensis, the fruits of Acacia nilotica, the shrubs of Sonchus oleraceus and the leaves of Azadirachta indica.

\section{CONCLUSION AND RECOMMENDATIONS:}

Risk factors for malaria are almost always concentrated in the lowest social and economic categories of societies. Poverty and poor environment in home and around lead to increase malaria incidence. The study found that the first factor lead to increase malaria is poor environment i.e. rare channels, stagnant water....etc.

The study found that income was the strongest influencing factor $(\mathrm{P}=0.000)$ affecting negatively the prevalence of Malaria among children through affecting standard of living and the type of measurement used to fight mosquitoes. Spray is effective measure to fight mosquitoes, but it's expensive and not available to most common people. Therefore, majority $(84.1 \%)$ of families who earns more than $300 \$$ using it. Also there is strong relation between environmental factors (such as pit latrine and home size) and prevalence of malaria.

The study recommended that the government must states policies to improve standards of living as general. Moreover primary health care must be appropriate, accessible, acceptable, and affordable and requires to common population. Because inadequate and unavailability may force mothers to search other solution to their families' health problem, even there are risk.

The people, NGOs and local committees should give the priority to preventive measures, this can done by a major role in controlling vectors of diseases. Moreover, must give big attention to sanitation environment. The people can participate in the different stages of mosquito control activities. This can be done by keeping the environment clean (home and surrounded areas).

\section{References}

Abbas, S (1994). Effect of environmental sanitation on child health. A comparative studies. Master of science in environmental studies. U of K. Sudan.

Abdalla, W. (2003). The socio-cultural, economic, and environment factors affecting health. PhD thesis. U of K. Sudan.

Abdalla S. I., Malik E. M. and Ali K. M. (2007). The burden of malaria in Sudan: incidence, mortality and disability adjusted life - years. Malaria Journal, 6: 97.

AHSR, 2011) 
Alsafi A. (1970). Native medicine in the Sudan. Sudan research unit, University of Khartoum, KUP. Sudan.

Ayele D. G, Zewotir T. T. and Mwambi H.G. (2013). Spatial distribution of malaria problem in three regions of Ethiopia. Malaria Journal , 12:207.

Ibn def alla, 1974), Altabagat.

Abd/ El-Gayoum S. M. E., El-Rayah E, Giha H. and A.El-Feki A (2009). Knowledge, practices and perceptions which affect acquiring malaria in man-made malarious area in Khartoum State, Sudan. Sudanese Journal of Public Health, 4 (1): 199-209.

Annual Health Statistics Reports (2011). Republic of Sudan Federal Ministry of Health National Health Information Centre.

Prathiba M. De Silva1 and John M. Marshall2 (2012). Factors Contributing to Urban Malaria Transmission in SubSaharan Africa: Journal of Tropical Medicine. Volume 2012 (2012), Article ID 819563, 10 pages.

Rasha A. Aal 1, Ayman A. Elshayeb 2 (2011). The Effects of Climate Changes on The Distribution and Spread of Malaria in Sudan. American Journal of Environmental Engineering. 1(1): 15-20.

Tarimo D.S. (2000). Mothers' perceptions and knowledge on childhood malaria in the holendemic Kibaha district, Tanzania: implications for malaria control and the IMCI strategy. Tropical Medicine \& International Health . Vol 5 Issue 3, P: 179-184.

Tusting L. S, Willey B, Lucas H, Thompson J., Kafy H.T, Smith R, Lindsay S.W(2013). Socioeconomic development as an intervention against malaria: a systematic review and meta-analysis. The Lancet. Volume 382, Issue 9896, Pages 963-972

WHO (2006). Preventing disease through healthy environments. Towards an estimate of the environmental burden of disease. WHO Library Cataloguing-in-Publication Data Prüss-Üstün, Annette. 